\title{
NON-GENETIC RISK FACTORS FOR THE FORMATION OF FACTOR VIII INHIBITORS IN HEMOPHILIA A PATIENTS IN THE DR. SOETOMO HOSPITAL SURABAYA
}

\author{
Intani Dewi Syahti Fauzi, Maria C Shanty Larasati, IDG Ugrasena \\ Department of Pediatrics, Faculty of Medicine, Universitas Airlangga/Dr. Soetomo Hospital, Surabaya, Indonesia. E-mail: \\ ugrasena56@gmail.com
}

\begin{abstract}
Neutralizing alloantibodies (inhibitors) are one of the complications that affect the morbidity and quality of life of hemophilia patient and can be caused by multiple factors. Genetic and inhibitors examination are not routinely performed and expensive. Therefore, identification of non-genetic factors is important to predict the formation of the inhibitors. To determine non-genetic risk factors for the formation of factor VIII inhibitors in children with Hemophilia A, a cross-sectional study of hemophilia children aged of 1-18 years at the Pediatric Hematology-Oncology Outpatient Clinic of the Dr. Soetomo Hospital Surabaya in March-April 2018 was carried out. Factors analyzed were the severity of hemophilia, early age of diagnosis, initial age of therapy, type of replacement therapy, frequency of factor VIII administration, and severity of bleeding by bleeding score. Statistical analysis using Chi-Square, Fisher, ANOVA, and logistic regression analysis was performed. A total of 29 children were evaluated as categorized as mild (7 children), moderate (15 children), and severe hemophilia (7 children). Inhibitors were found in 11 subjects, with 7 and 4 of them showed low (1-5 BU) and high titer (> $5 \mathrm{BU}$ ), respectively. The initial age of diagnosis $\leq 1$ year was associated with the formation of factor VIII inhibitors (OR 8.75; 95\% CI=1.5-50.2; $p=0.015$ ). The severity of hemophilia, early age of therapy, type of replacement therapy, frequency of therapy, and the bleeding score was not significantly associated with the formation of factor VIII inhibitors. The initial age of diagnosis of less than one year was a significant risk factor for the formation of factor VIII inhibitors.
\end{abstract}

Key words: Hemophilia A, factor VIII, factor VIII inhibitor, nongenetic risk factors

\section{INTRODUCTION}

Hemophilia is a bleeding disorder due to hereditary coagulation abnormalities, inherited by $X$-linked recessive. ${ }^{1-3}$ Replacement therapy in Hemophilia A patients with factor VIII is by recombinant or plasma derivatives given both on-demand and prophylaxis. ${ }^{4-6}$ One of the severe complications in hemophilic patients is the formation of neutralizing alloantibodies or inhibitors that affect the patient's morbidity and quality of life. ${ }^{2,4}$ Prevalence of factor VIII inhibitors in hemophilia patients varies greatly, but overall ranges are from $3.6 \%$ to $52 \%$. The prevalences of inhibitors in Taiwan, Jordan, and Saudi Arabia are 10.4\%, 9\%, $9.7 \%$, respectively, whereas the prevalences in Indonesia vary from $35 \%$ to $37.5 \%{ }^{1,6-8}$ Inhibitors are problem in management of hemophilia because treatment becomes difficult and expensive. ${ }^{2}$

The factor VIII Inhibitors are immunoglobulin G which can neutralize factor VIII activity in hemophilia patients. ${ }^{3,4,8,9}$ The mechanism of factor VIII inhibitors formation is multifactorial and can further be classified into genetic and environmental factors. ${ }^{4,6,10-12}$ Evaluation of inhibitor levels is not routinely carried out in Indonesia because the required facilities are limited and the costs are expensive. ${ }^{8}$

Until now, there are still no published data regarding the non-genetic risk factors for the formation of factor VIII inhibitors in the Dr. Soetomo Hospital Surabaya. The purpose of this study was to evaluate the severity of hemophilia, initial age at diagnosis, initial age of therapy, type of replacement therapy, frequency of replacement therapy, and bleeding score associated with the formation of factor VIII inhibitors in children with hemophilia in the Dr. Soetomo Hospital.

\section{METHODS}

This study was a cross-sectional study using data from medical records of hemophilia children aged 1-18 years who had factor VIII inhibitors at the Pediatric Hematology-Oncology Outpatient Clinic of 
the Dr. Soetomo Hospital, Surabaya during March-April 2018. All patients who had been diagnosed with hemophilia $A$ and had inhibitors data were involved in this study. Hemophilia A was classified as severe hemophilia A (factor VIII <1\%), moderate (factor VIII 1-5\%), and mild (factor VIII 5-30\%). Measurement of factor VIII inhibitor was performed in the previous study using Bethesda assay and classified as high titer inhibitors ( $>5$ Bethesda Unit (BU)), low titer inhibitors (1 -5 BU) and negative inhibitors. Subjects were excluded if they received immunosuppressant and steroid therapy and did not have factor VIII inhibitor data in medical records. Factors analyzed were the severity of hemophilia, early age of diagnosis, initial age of therapy, type of replacement therapy, frequency of factor VIII administration, and severity of bleeding by bleeding score. SPSS ver. 21, Chi-Square, Fisher, ANOVA, and logistic regression test were used for statistical analysis. The study was approved by the Health Research Ethics Committee Dr. Soetomo Hospital, Surabaya with number of 0049/KEPK/ II/2018.

\section{RESULTS AND DISCUSSION}

From 29 children with hemophilia and inhibitor levels in medical records, mean age of 10.2 (SD 3.93) years was obtained. The youngest subject was 4 years old, while the oldest was 18 years old. In this study, all subjects received therapy on demand. Among 29 patients, there were 10 (34.5\%) subjects who started exogenous factor VIII replacement therapy starting from the infant age (0-1 years). Almost all subjects received factor VIII concentrate (Koate $\left.{ }^{\circledR}\right)$ therapy, but only two patients received a combination of therapy with factor VIIa one time. Based on the severity of hemophilia A, 7 (24.1\%) subjects were classified as mild, $15(51.7 \%)$ subjects were classified as moderate, and 7 (24.1\%) subjects were classified as severe hemophilic patients. In this study, 11 (37.93\%) subjects had inhibitors (positive inhibitors) with a distribution of between $1.7 \mathrm{BU}$ and $7.2 \mathrm{BU}$. Of the 11 subjects with positive inhibitors, 7 (63.64\%) subjects had low titer inhibitors (1-5 BU) and $4(36.36 \%)$ subjects had high titer inhibitors (> 5 $\mathrm{BU})$. Bivariate analysis using Fischer exact test showed the degree of bleeding $(p=0.051)$, age of initiation of therapy $(p=0.62)$, type of replacement therapy $(p=0.623)$, frequency of therapy $(p=0.831)$, while ANOVA test showed no statistically significant correlation between the degree of bleeding and factor VIII inhibitor levels with mean $17.413 \pm 5.017$ $(p=0.78)$. The majority of high titer inhibitors were found at the age of 3-6 years, whereas no inhibitors were mostly found in the age group above 6 years. There was a statistically significant correlation between current age and factor VIII inhibitor levels $(p=0.038)($ Table 1$)$.

The degree of bleeding in this study was assessed by using a bleeding score from Bleeding Assessment Tools (BATs) standardized by the International Society on Thrombosis and Hemostasis working group-Bleeding Assessment Tool, ISTH/SSC Subcommittees on vWF and on Perinatal/Pediatric Hemostasis (ISTH/SSC-BAT). All subjects had abnormal values above the cut-off $\geq 3$ in children. The lowest value, the highest value, mean value, and median value were $6,32,17.413 \pm 5.017$ and 16 , respectively. The bleeding score data were normally distributed based on one-sample Kolmogorov-Smirnov test and Shapiro-Wilk test. After analyzed using ANOVA, there was no significant difference in bleeding score based on inhibitor levels ( $p=0.780$ ) (Table 2 ).

The variable logistic regression analysis was grouped into two categories and $2 \times 2$ tables were used to meet the requirements of logistic regression analysis. In this study, it was found that patients diagnosed and receiving initial therapy at age of 0-1 years, were likely to have a positive inhibitor 8.75 times greater than patients diagnosed at the age of $>1$ year with a statistical significance $p=0.015$ and 95\% CI (1.528-50.112) (Table 3).

The subjects of this study comprised 29 boys who suffered from hemophilia A. Hemophilia itself was inherited X-linked recessively so that it only manifested in males, while females only became carriers or carriers of the nature of the disease. ${ }^{3,13}$ Study by Simatupang et al. in 2013 regarding the risk factors for the formation of factor VIII inhibitors in the Cipto Mangunkusumo Hospital, showed the median (range) age of the study subjects of 10 (1.5-18) years. ${ }^{8}$ The highest severity of hemophilia found in this study was moderate hemophilia (1-5\% factor VIII level) reported in 15 (51.71\%) subjects followed by mild hemophilia reported in 7 (24.1\%) subjects. Based on clinical symptoms and factor VIII levels, hemophilia A was differentiated into severe hemophilia A (FVIII $<1 \%$ ), moderate (FVIII 1-5\%), and mild (FVIII 5-30\%). ${ }^{9}$

In this study, all subjects received therapy on demand. From 29 patients, 10 (34.5\%) patients started receiving exogenous factor VIII replacement therapy at infant age (0-1 years). Almost all subjects received factor VIII concentrated therapy (Koate ${ }^{\circledR}$ ) 
Table 1. Characteristics of subjects based on the formation of factor VIII inhibitors

\begin{tabular}{|c|c|c|c|c|c|}
\hline \multirow{3}{*}{ Parameter } & \multirow{3}{*}{$\begin{array}{c}\text { Negative } \\
\mathrm{n}=18\end{array}$} & \multicolumn{3}{|c|}{ Factor VIII Inhibitor } & \multirow{3}{*}{$\mathrm{P}$} \\
\hline & & \multicolumn{2}{|c|}{ Positive } & \multirow{2}{*}{$\begin{array}{l}\text { Total } \\
n=29\end{array}$} & \\
\hline & & $\begin{array}{c}\text { Low titer } \\
n=7\end{array}$ & $\begin{array}{c}\text { High titer } \\
n=4\end{array}$ & & \\
\hline Severity of hemophilia & & & & & 0.051 \\
\hline Mild & $7(100)$ & 0 & 0 & $7(100)$ & \\
\hline Moderate & $9(60)$ & $3(20)$ & $3(20)$ & $15(100)$ & \\
\hline Severe & $2(28.6)$ & $4(57.1)$ & $1(14.3)$ & $7(100)$ & \\
\hline Age & & & & & 0.038 \\
\hline $3-6$ years & $1(16.7)$ & $2(33.3)$ & $3(50)$ & $6(100)$ & \\
\hline $6-12$ years & $8(72.7)$ & $3(27.3)$ & 0 & $11(100)$ & \\
\hline $12-18$ years & $9(75)$ & $2(16.7)$ & $1(8.3)$ & $12(100)$ & \\
\hline Initial age of diagnosis & & & & & 0.007 \\
\hline $0-1$ years & $3(30)$ & $3(30)$ & $4(40)$ & $10(100)$ & \\
\hline $2-3$ years & $8(88.9)$ & $1(11,1)$ & 0 & $9(100)$ & \\
\hline $3-6$ years & $6(100)$ & 0 & 0 & $6(100)$ & \\
\hline $6-12$ years & 0 & $1(100)$ & 0 & $1(100)$ & \\
\hline $12-18$ years & $1(33.3)$ & $2(66.7)$ & 0 & $3(100)$ & \\
\hline Initial age of therapy & & & & & 0.62 \\
\hline $0-1$ years & $3(30)$ & $3(30)$ & $4(40)$ & $10(100)$ & \\
\hline $2-3$ years & $8(88.9)$ & $1(11.1)$ & 0 & $9(100)$ & \\
\hline $3-6$ years & $4(100)$ & 0 & 0 & $4(100)$ & \\
\hline $6-12$ years & $1(50)$ & $1(50)$ & 0 & $2(100)$ & \\
\hline $12-18$ years & $2(50)$ & $2(50)$ & 0 & $4(100)$ & \\
\hline Replacement therapy & & & & & 0.623 \\
\hline Factor VIII & $17(63)$ & $6(22.2)$ & $4(14.8)$ & $27(100)$ & \\
\hline Factor VIIa & $1(50)$ & $1(50)$ & 0 & $2(100)$ & \\
\hline Frequency therapy/month & & & & & 0.831 \\
\hline$<4 \mathrm{x}$ & $13(65)$ & $4(20)$ & $3(15)$ & $20(100)$ & \\
\hline $4-5 x$ & $4(57.1)$ & $2(28.6)$ & $1(14.3)$ & $7(100)$ & \\
\hline$>5-8 x$ & $1(50)$ & $1(50)$ & 0 & $2(100)$ & \\
\hline
\end{tabular}

but only two patients had a history of receiving a combination therapy with factor VIIa for one time. Current recommendation by WFH for management of hemophilia A is prophylactic therapy with administration of clotting factor concentrates of 25-40 IU/kg three times a week and twice a week for patients with hemophilia B. This protocol cannot be applied in Indonesia with cost as the main problem. ${ }^{7,14}$ For hemophilia A patients with positive inhibitors, administration of bypassing agents such as Activated Prothrombin Complex Concentrates
(aPCC) and recombinant activated factor VII concentrates are needed for acute bleeding. Bypassing agents is needed in the long term for eradication of inhibitors and enables patients to receive the administration of factor VIII concentrates. ${ }^{15}$ Until now there is no literature that discusses the effect of delayed therapy on the onset of inhibitors.

The prevalence of inhibitors in this study was $37.93 \%(11 / 29)$ with a distribution between $1.7 \mathrm{BU}$ and $7.2 \mathrm{BU}$. Of the 11 subjects with positive 
Table 2. Bleeding score with factor VIII inhibitors

\begin{tabular}{|c|c|c|c|c|c|c|c|}
\hline \multirow{3}{*}{ Inhibitor } & \multicolumn{6}{|c|}{ Bleeding Score } & \multirow{3}{*}{$\mathbf{p}$} \\
\hline & \multirow{2}{*}{$\mathbf{N}$} & \multirow{2}{*}{ Mean \pm SD } & \multirow{2}{*}{ Minimum } & \multirow{2}{*}{ Maximum } & \multicolumn{2}{|c|}{ CI 95\% for mean } & \\
\hline & & & & & $\begin{array}{l}\text { Lower } \\
\text { Bound }\end{array}$ & $\begin{array}{l}\text { Upper } \\
\text { Bound }\end{array}$ & \\
\hline $\begin{array}{c}\text { Negative } \\
\text { Inhibitor (0) }\end{array}$ & 18 & $16.94 \pm 5.53$ & 6.00 & 32.00 & 14.19 & 19.69 & 0.780 \\
\hline $\begin{array}{l}\text { Low titer } \\
\text { Inhibitor } \\
(1-5 \mathrm{BU})\end{array}$ & 7 & $18.57 \pm 4.99$ & 12.00 & 26.00 & 13.95 & 23.19 & \\
\hline $\begin{array}{l}\text { High titer } \\
\text { Inhibitor } \\
(>5 \mathrm{BU})\end{array}$ & 4 & $17.50 \pm 2.64$ & 15.00 & 21.00 & 13.29 & 21.71 & \\
\hline Total & 29 & $17.41 \pm 5.01$ & 6.00 & 32.00 & 15.50 & 19.32 & \\
\hline
\end{tabular}

Table 3. Logistic regression analysis of two categories of variables

\begin{tabular}{|c|c|c|c|c|c|c|c|c|c|}
\hline & & \multicolumn{2}{|c|}{$\begin{array}{l}\text { Negative } \\
\text { Inhibitor }\end{array}$} & \multicolumn{2}{|c|}{$\begin{array}{l}\text { Positive } \\
\text { Inhibitor }\end{array}$} & \multirow[t]{2}{*}{$\mathbf{P}$} & \multirow[t]{2}{*}{ OR } & \multicolumn{2}{|c|}{$95 \%$ CI } \\
\hline & & $n$ & $\%$ & $n$ & $\%$ & & & Min & Max \\
\hline $\begin{array}{l}\text { Age } \\
\text { (years) }\end{array}$ & $\begin{array}{l}<12 \text { (1) } \\
\geq 12 \text { (ref.group) }\end{array}$ & $\begin{array}{l}9 \\
9\end{array}$ & $\begin{array}{l}31.0 \\
31.0\end{array}$ & $\begin{array}{l}8 \\
3\end{array}$ & $\begin{array}{l}27.6 \\
10.3\end{array}$ & 0.345 & & & \\
\hline $\begin{array}{l}\text { Initial age of } \\
\text { diagnosis } \\
\text { (years) }\end{array}$ & $\begin{array}{l}0-1(1) \\
>1 \text { (ref.group) }\end{array}$ & $\begin{array}{c}3 \\
15\end{array}$ & $\begin{array}{l}10.3 \\
51.7\end{array}$ & $\begin{array}{l}7 \\
4\end{array}$ & $\begin{array}{l}24.1 \\
13.8\end{array}$ & 0.015 & 8.750 & 1.528 & $\begin{array}{c}50.11 \\
2\end{array}$ \\
\hline $\begin{array}{l}\text { Replacement } \\
\text { therapy }\end{array}$ & $\begin{array}{l}\text { Factor VIII (1) } \\
\text { Factor VIIa } \\
\text { (ref.group) }\end{array}$ & $\begin{array}{c}17 \\
1\end{array}$ & $\begin{array}{c}58.6 \\
3.4\end{array}$ & $\begin{array}{c}10 \\
1\end{array}$ & $\begin{array}{c}34.5 \\
3.4\end{array}$ & 0.759 & & & \\
\hline $\begin{array}{l}\text { Frequency } \\
\text { therapy } \\
\text { (time/month) }\end{array}$ & $\begin{array}{l}<4 \text { (1) } \\
\geq 4 \text { (ref.group) }\end{array}$ & $\begin{array}{c}12 \\
5\end{array}$ & $\begin{array}{l}44.4 \\
18.5\end{array}$ & $\begin{array}{l}6 \\
4\end{array}$ & $\begin{array}{l}22.2 \\
14.8\end{array}$ & 0.738 & & & \\
\hline $\begin{array}{l}\text { Bleeding } \\
\text { score }\end{array}$ & $\begin{array}{l}\leq 16(1) \\
>16 \text { (ref.group) }\end{array}$ & $\begin{array}{l}9 \\
9\end{array}$ & $\begin{array}{l}31.0 \\
31.0\end{array}$ & $\begin{array}{l}6 \\
5\end{array}$ & $\begin{array}{l}20.7 \\
17.2\end{array}$ & 0.433 & & & \\
\hline
\end{tabular}

inhibitors, 7 (63.64\%) subjects had low titer inhibitors (1-5 BU) and 4 (36.36\%) subjects had high titer inhibitors ( $>5 \mathrm{BU})$. The prevalence of factor VIII inhibitors in hemophilia A patients varies, ranging from $3.6 \%-52 \%$. The results of this study were almost the same as other studies in Indonesia by Harijadi, et al. in RSCM in 2004 who showed a prevalence of inhibitors of $35 \%$ and study by Simatupang et al. at Cipto Mangunkusumo Hospital that showed a prevalence of inhibitors of $37.5 \%$. The prevalence was still lower compared to the results of a study by Saifuddin, et al. in 2012-2013 in the population of hemophilia A in West Java with a positive prevalence of $81.0 \%$ inhibitors. ${ }^{1,6,8,16}$ Gouw et al. in the Netherlands, 2013 showed $32.0 \%$ incidence of inhibitor formation among 606 severe hemophilia $A$ patients born between 2000 and $2010 .{ }^{17}$ The process of inhibitors formation is multifactorial, consisting of genetic and environmental factors. Several studies have been performed to determine the factors that play a role in the emergence of inhibitors, but there are still differences of opinion. ${ }^{8,18,19}$

In this study, there was no statistically significant correlation between the degree of hemophilia and the formation of factor VIII inhibitors ( $p=0.051)$. To date, it was known that most inhibitors were found in patients with severe hemophilia A compared with moderate or mild hemophilia A. In the Simatupang et al. study, almost all subjects (14/15) with positive inhibitors were severe hemophilia patients. The study found no correlationn between the degree of hemophilia and the emergence of inhibitors 
$(p=1.00)^{8,14,19}$ Saifudin, et al. also found that in West Java 55 subjects among 69 patients with positive inhibitors were severe hemophilia patients. However, no correlation was found between the degree of hemophilia and the occurrence of inhibitors $(p=0.202){ }^{8}$ Another study by Addiego et al. showed similar results, with the prevalence of 3$13 \%$ inhibitors in mild and moderate hemophilia patients. ${ }^{4}$ In this study, 6 subjects from total 11 patients with positive inhibitors were moderate hemophilia patients characterized by the presence of 2 types of inhibitors. There are two kinetics of factor VIII inhibitor, namely type 1 and 2. Type 1 inhibitors (type 1 kinetics or simple kinetics) neutralize FVIII completely and then neutralize themselves so that they do not react with factor VIII from the next replacement therapy. Type 1 inhibitors are dose-dependent in a linear fashion (the higher the level, the faster the neutralization of factor VIII). Type 2 inhibitors (type 2 kinetics or complex kinetics) neutralize FVIII incompletely but not themselves, so they still have the ability to neutralize factor VIII from subsequent replacement therapy. Type 1 inhibitors are more common in severe hemophilia, whereas type 2 inhibitors are more commonly found in mild and moderate hemophilia., ${ }^{2,420,21}$

In this study, the majority of high titer inhibitors were found at the age of 3-6 years, whereas mostly no inhibitors were found in the group with age. There was a statistically significant correlation between current age and factor VIII inhibitor levels $(p=0.0038)$. Study by Hay et al. found the highest incidence of inhibitors in children aged 0-4 years and $>60$ years. Another study in Indonesia by Harijadi et al. at RSCM found the highest incidence of inhibitors in 8 children aged $6-12$ years out of 16 subjects. Study by Gouw et al. found positive inhibitor in 179 subjects among 606 hemophilia A patients. The formation of inhibitors occurs at a median age of 15.5 months with a range of 8 days to 6.8 years. ${ }^{17}$ After each variable was classified into two categories, in this study, patients at the age of 0-1 years were 8.75 times more likely to have positive inhibitors than patients diagnosed at the age of $>1$ year with a statistical significance $p=0.015$ and $95 \%$ $\mathrm{CI}(1.528-50,112)$. Previous studies that classified age of patients when first diagnosed and received first-time replacement therapy at age of 0-6 year(s), 6-12 months, $>1$ year found a correlation between the age when receiving therapy and the onset of inhibitors. The incidence of inhibitor formation was higher in those who received replacement therapy before age of 6 months. There was 41\%,29\%, and
$12 \%$ increase of inhibitors if replacement therapy was given at age of $<6$ months, between 6-12 months, and $>12$ months. ${ }^{2,8,22}$ This study showed the same results with a cohort study by Gouw et al. ${ }^{17}$ The difference of the results in some of these studies were possibly due to the type of replacement therapy or the mutation of certain genes. The most common type of gene mutation in patients treated at an early age is 22 inversions, therefore, it was suspected that these gene mutations mostly affected the emergence of inhibitors. ${ }^{6,8,22}$

Severe genetic defects such as the presence of large deletions in the factor VIII gene, inversion (especially intron 22 inversions), and stop mutation are associated with a high risk of inhibitors compared to small deletions/insertions, missing mutations or splice site mutations. The results of the CANAL study showed that patients with severe genetic defects had a risk of inhibitor formation three times greater than patients with a low-risk genetic mutation. ${ }^{18}$ In the group that had received therapy with a combination of factor VIIa, there was 1 (50\%) subjects with low titer inhibitors among 2 patients. There was no significant correlation between the type of replacement therapy and the factor VIII inhibitor level $(p=0.623)$. The important potential difference between the concentrated products begins with the introduction of concentrates with inactivated viruses, namely recombinant factor VIII (rFVIII) and plasma-derived factor VIII (pdFVIII). ${ }^{17}$ This was different from the Concerted Action on Neutralizing Antibodies in severe hemophilia A (CANAL) study which found no significant correlation bewtween administration of pdFVIII and rFVIII and risk factors for inhibitor formation. The CANAL study reported a reduced risk of inhibitors in patients receiving prophylactic therapy compared to therapy on demand. ${ }^{4,17}$ Several studies have reported that the development of inhibitors was lower in hemophilia A patients who received pdFVIII containing von Willebrand factor (VWF) compared to those treated with rFVIII. ${ }^{18}$ According to Gouw demand, this was related to the content of the transforming growth factor B (TGF B) and VWF obtained in several types of plasma concentrates. As with the VWF, TGF $B$ factor is capable of being protective against the emergence of factor VIII inhibitor antibodies because it is able to protect the factor VIII (C2) domain as the common target of damage by factor VIII antibodies. In addition, some recombinant factors also do not have a VWF factor which is protective against factor VIII inhibitors. ${ }^{23}$ Gouw et al. study showed that regular prophylactic administration showed a $60 \%$ lower 
risk of inhibitors formation than therapy on demand. ${ }^{2,4,17}$ The formation of inhibitors is a complex immune response that depends not only on genetic factors but also on other risk factors related to therapy. The intensity of first exposure to FVIII factor was postulated as a risk factor for inhibitor formation because significant inflammation or cell injury causes immunological "danger signals" that stimulate "antigen-presenting" cells and strengthen immunological responses that cause inhibitor formation. ${ }^{4,24-26}$

In this study, all subjects at children age had abnormal values above the cut-off $\geq 3$. The lowest value, the highest value, the mean value, and the median value were 6, 32, w 17.413 \pm 5.017 , and 16, respectively. There was no significant difference in bleeding score based on inhibitor levels $(p=0.780)$. Thus, the cut-off for positive or abnormal BS was $\geq 4$ in adult male, $\geq 6$ in adult female and $\geq 3$ in children. ${ }^{27}$ Study by Mahdi revealed that ISTH-BAT was able to help diagnose bleeding conditions in hemophilia patients and could be considered a predictor of bleeding risk or severity with the mean BAT of $12.8 \pm 8.2$ in hemophilia $A{ }^{28}$ The limitations of this study were that the small number of samples and onetime examination of factor VIII inhibitor was the only data taken from the medical records.

\section{CONCLUSION AND SUGGESTION}

Age of of initial diagnosis less than one year was a significant risk factor for the formation of factor VIII inhibitors. A further prospective cohort study in assessments of non-genetic risk factors, serial levels of factor VIII inhibitors and further studies on genetic and epigenetic mapping to determine the risk of formation of factor VIII inhibitors were needed.

\section{REFERENCES}

1. Harijadi, DG, Arwin A, Akib. The prevalence of factor VIII inhibitor in patients with severe hemophilia $A$ and its clinical characteristics. Paediatrica Indonesiana, 2005; 45(7): 177-82.

2. Yantie VK, Ariawati K. Inhibitor pada hemofilia. Medicina, 2002; 43(1): 31-6.

3. Aznar J, Moret AFFI, Vila C, Cabrera N, Mesa E, Bonanad S. Inhibitor development after switching of FVIII with severe hemophilia A. Haemophilia, 2014; 20(5): 624-9.

4. Witmer C, Young G. Factor VIII inhibitors in hemophilia A: Rationale and latest evidence. Ther Adv Hematol, 2013; 4(1): 59-72.

5. Gomez K, Klamroth R, Mahlangu J, Mancuso M,
Mingot $M$, Ozelo $M$. Key issues in inhibitor management in patients with hemophilia. Blood Transfus, 2014; 12(1): 319-29.

6. Saifudin, Achmad H, Reniarti. Faktor risiko non-genetik inhibitor faktor VIII pada pasien hemofilia A. Sari Pediatri, 2015; 17(2): 119-23.

7. Septarini A, Windiastuti E. Terapi profilaksis versus on-demand pada pasien hemofilia berat dengan hemartrosis. Sari Pediatri, 2010; 11(5): 311-6.

8. Simatupang $G$, Windiastuti E, Oswari H. Faktor risiko timbulnya inhibitor faktor VIII pada anak dengan hemofilia A. Sari Pediatri. 2013; 14(5): 1-7.

9. Dekoven $M$, Wisniewski T, Petrilla A, Holot N, Lee W, Cooper D, Von Mackensen S. Health-related quality of life in hemophilia patients with inhibitors and their caregivers. Haemophilia. 2013; 19(2): 287-93.

10. Astermark J. Why do inhibitors develop? principles of and factors influencing the risk for inhibitor development in hemophilia. Haemophilia, 2006; 12(3): 52-60.

11. Genderen FV, Meeteren NV, Bom JVD, Heijnen $L$, Kleijn PD, Berg HVD, Helders PJ. Functional consequences of hemophilia in adults: The development of the hemophilia activities list. Haemophilia, 2004; 10(5): 565-71.

12. Gomez K, Klamroth R, Mahlangu J, Mancuso M, Mingot $M$, Ozelo $M$. Key issues in inhibitor management in patients with hemophilia. Blood Transfus, 2014; 12(1): 319-29.

13. Bagheri S, Beheshtipoor N, Rambod M, Karimi M, Zare N, Hashemi F. The quality of life of children with hemophilia in Shiraz, Iran. IJCBNM, 2013; 1(2): 1-10.

14. World Federation of Hemophilia Treatment Guidelines Working Group. Guidelines for the management of hemophilia. Montreal, Blackwell Publishing Ltd, 2012; 1-73.

15. Kreuz W, Ettingshausen C. Inhibitors in patients with hemophilia A. Thromb Res, 2014; 134(1): 22-6.

16. Hay C, Palmer B, Chalmers E. Incidence of factor VIII inhibitors throughout life in severe hemophilia $A$ in the United Kingdom. Blood, 2011; 117(23): 6367-70.

17. Gouw SC, Bom JGVD, Berg MV. Treatment-related risk factors of inhibitor development in previously untreated patients with hemophilia A: The CANAL cohort study. Blood, 2007; 109: 4648-54.

18. Berg HVD. Risk of inhibitor development in children with hemophilia A. European Haematology Review. 2007;1(1):8-10.

19. Ragni M, Ojeifo O, Feng J. Risk factors for inhibitor formation in hemophilia: A prevalent case-control study. Haemophilia, 2009; 15(5): 1074-82.

20. Lacroix-Desmazes S, Misra N, Bayry J, Artaud C, Drayton B, Kaveri S, Kazatchkine. Pathophysiology of inhibitors to factor VIII in patients with hemophilia A. Haemophilia, 2002; 8(3): 273-9.

21. Ma $A D$, Carrizosa D. Acquired factor VIII inhibitors: Pathophysiology and treatment. Hematology Am Soc Hematol Educ Program, 2006; 1: 432-7.

22. Chalmers E, Brown S, Keeling D. Early factor VIII 
exposure and subsequent inhibitor development in children with severe hemophilia A. Hemophilia, 2007; 13(1): 149-55.

23. Goudemand J, Rothschild C, Demiguel V. Influence of the type of factor VIII concentrate on the incidence of factor VIII inhibitors in previously untreated patients with severe hemophilia A. Blood, 2006; 107(1): 46-51.

24. Gallucci $P$, Matzinger $P$. Danger signals: SOS to the immune system. Curr Opin Immunol, 2001; 13: 114-9.

25. Kono $H$, Rock K. How dying cells alert the immune system to danger. Nat Rev Immuno, 2008; 8: 279-9.
26. Matzinger P. The danger model: A renewed sense of self. Science, 2002; 296: 301-5.

27. Elbatarny $M$, Mollah S, Grabell. Normal range of bleeding scores for the ISTH-BAT: Adult and pediatric data from the merging project. Haemophilia, 2014; 20(6): 831-5.

28. Shahriari M, Karimi M. Are bleeding scores predicting severity and outcome in hemophilia and rare bleeding disorders?. Blood, 2016; 128: 4801. 